\title{
Original Research \\ What Design Features Are Used in Effective e-Health Interventions? A Review Using Techniques from Critical Interpretative Synthesis
}

AU1 Leanne G. Morrison, Ph.D., ${ }^{1}$ Lucy Yardley, Ph.D., ${ }^{1}$ John Powell, Ph.D., ${ }^{2}$ and Susan Michie, Ph.D. ${ }^{3}$

${ }^{1}$ School of Psychology, University of Southampton, Southampton, United Kingdom.

${ }^{2}$ Division of Health Sciences, Warwick Medical School, University of Warwick, Warwick, United Kingdom.

${ }^{3}$ Research Department of Clinical, Educational and Health

Psychology, University College London, London, United Kingdom.

\begin{abstract}
The effectiveness of e-health interventions varies greatly. Despite this, there has been relatively little formal consideration of how differences in the design of an intervention (i.e., how the content is delivered) may explain why some interventions are more effective than others. This review primarily examines the use of the Internet to provide educational and self-management interventions to promote health. The article develops hypotheses about how the design of these interventions may be associated with outcomes. In total, 52 published reports from both a diversity sample and a representative sample were reviewed using techniques from critical interpretative synthesis. Four core interactive design features were identified that may mediate the effects of intervention design on outcomes: Social context and support, contacts with intervention, tailoring, and self-management. A conceptual framework to summarize the design of e-health interventions delivered using the Internet is proposed. The framework provides a guide for systematic research to identify the effects of specific design features on intervention outcomes and to identify the mechanisms underlying any effects. To optimize the design of e-health interventions more work is needed to understand how and why these design features may affect intervention outcomes and to investigate the optimal implementation and dosage of each design feature.
\end{abstract}

Key words: e-health, technology, telehealth

\section{Introduction}

\footnotetext{
he term "e-health" describes a range of information and communication technologies that are used to provide healthcare, ${ }^{1}$ such as Internet or computer-based technologies, telemedicine, remote patient monitoring, electronic health records, and videoconferencing. This review will focus primarily on the use of the Internet to provide educational and selfmanagement interventions that support users and patients to change
}

health-related behaviors. Using the Internet to deliver health interventions currently has a small but significant overall effect on behavior. ${ }^{2-4}$ However, the reported efficacy and effectiveness of individual interventions vary hugely. ${ }^{5}$ Effectiveness may be improved by optimizing the design of interventions, that is, the ways in which the content of an intervention is delivered.

There are already well-established frameworks to guide development of the content of health interventions. ${ }^{6-8}$ These need to be supplemented by frameworks to guide how that content should be delivered using digital communication technologies like the Internet. Existing frameworks have identified a range of design features that may influence users' satisfaction and behavior change. ${ }^{8-12}$ However, these frameworks do not provide a comprehensive description of design features that can be used to deliver interventions and have not systematically examined how specific features contribute to outcomes.

The design features of published Internet-based health interventions are not always explicitly described or systematically varied, which precludes definitive hypothesis testing of the effects of design features on outcomes. This review aims to develop a conceptual framework to define the range of design features that could be used to deliver the content of health interventions delivered using the Internet. The purpose of developing this conceptual framework is to permit analysis of how specific feature(s) of intervention design may influence health-related outcomes. We will develop hypotheses and questions about possible associations between intervention design and outcomes that should be addressed by future research. We used techniques from critical interpretive synthesis (CIS), an approach to review that is well suited to the task of hypothesis generation.

\section{Methods}

CIS $^{13}$ provides an appropriate methodological alternative to Cochrane-style systematic review ${ }^{14}$ when the literature is not suitable for meta-analysis. CIS uses techniques from qualitative research (e.g., diversity sampling, constant comparison, deviant case analysis, theoretical saturation ${ }^{15}$ ) to guide a dynamic and iterative approach to the review process. CIS does not use the conventional search processes of the systematic review (e.g., exhaustive searching for all available articles, rigid inclusion and exclusion criteria, quality assessments). Instead, the aim is to identify and select a diverse sample of articles to represent the variation found within the literature. To identify and compare the range of design features used to deliver Internet-based health interventions we collected a diversity sample, a theoretical sample, and a representative sample of articles (see Fig. 1). 


\section{MORRISON ET AL.}

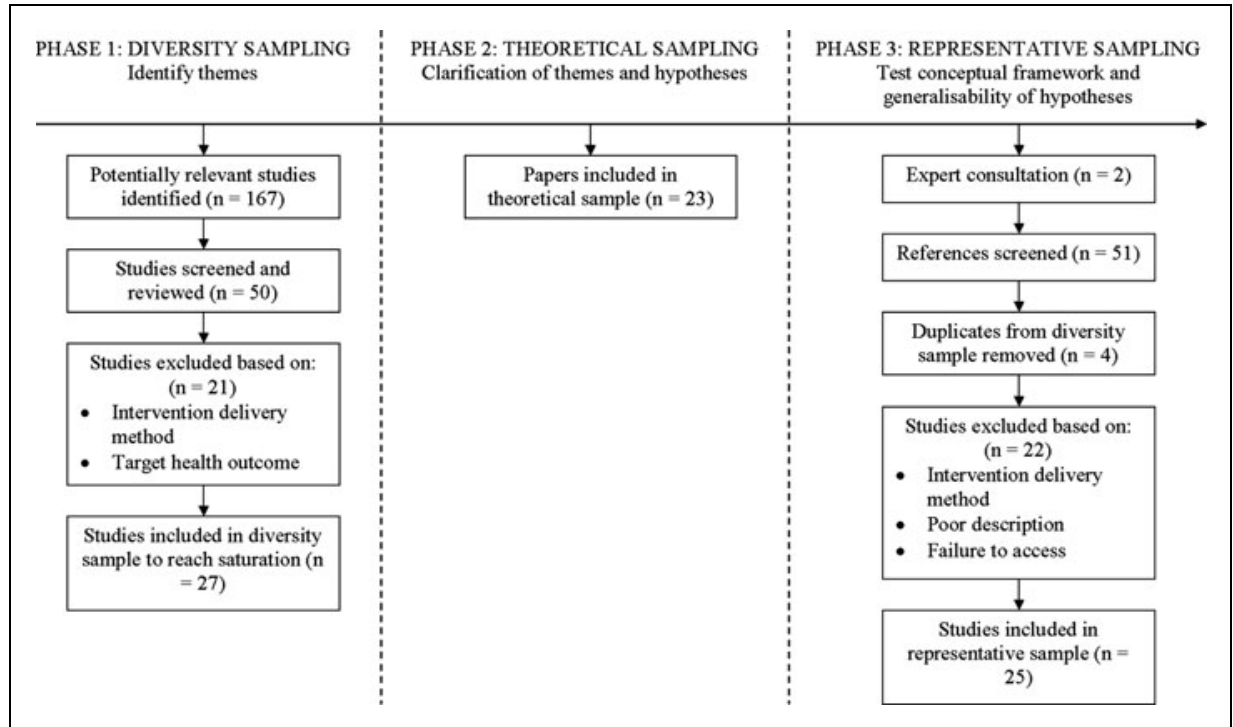

Fig. 1. Flow chart for the identification and selection of studies.

\section{PHASE 1. DIVERSITY SAMPLING}

Aim. To select a sample of articles, which used a diverse range of design features to deliver Internet-based health interventions.

Inclusion criteria. Included were articles published between 2000 and 2009 reporting quantitative analyses of fully automated Internetbased health interventions.

Exclusion criteria. Excluded were computer-based interventions, interventions delivered solely by synchronous computer-mediated communication, interventions delivered by face-to-face contact, or interventions designed specifically to treat mental health disorders. These criteria ensured that diversity in the design of interventions was examined in a homogeneous sample.

Search strategy. Studies were identified between June and September 2009 using electronic bibliographic databases: Ovid, ISI Web of Knowledge, PubMed, Science Direct, and Google scholar. Reference, related article, and cited article lists were checked for additional relevant studies. Search terms were as follows: Internet; health; intervention; quantitative; behavior; review; efficacy; evaluation; use. Sampling ceased when no substantially different design features were identified from including further articles (i.e., when saturation was achieved). ${ }^{16}$ Twenty-seven articles were included in the final diversity sample, reporting interventions for physical activity, ${ }^{17-29}$ smoking cessation, ${ }^{30-34}$ weight, ${ }^{35-37}$ physical activity and nutrition, ${ }^{38}$ nutrition, ${ }^{39}$ chronic pain, ${ }^{40}$ dyspnea, ${ }^{41}$ arthritis, ${ }^{42}$ and breast cancer risk. ${ }^{43}$ Four of these programs contained telemedicine components. ${ }^{30,35,40,41}$

Review strategy. The design features used to deliver interventions were first identified. The associations between the presence of design features and intervention effectiveness were then examined, paying attention to possible reasons for variability in the effect of design features. The output for Phase 1 was as follows: The development of a conceptual framework to summarize the design features used in Internet-based interventions; the generation of hypotheses about the potential association between design features and intervention outcomes; and identification of research questions to address unresolved issues. In order to generate hypotheses, interventions were coded as more effective, less effective, or ineffective (see Table 1). The diversity sample contained 15 more effective interventions, ${ }^{18,20,21,25-31,34-37,41} 11$ less effective interventions, ${ }^{17,19,22-24,32,33,38-40,42}$ one intervention reporting only process evaluations, ${ }^{43}$ and no ineffective interventions.

\section{PHASE 2: THEORETICAL SAMPLING}

Aim. To clarify the classification of design features identified during Phase 1 and provide further insight as to the possible reasons for variability in the effect of design features.

\begin{tabular}{|c|c|}
\hline $\begin{array}{l}\text { INTERVENTION } \\
\text { CODE }\end{array}$ & CRITERIA \\
\hline \multirow[t]{3}{*}{ More effective } & $\begin{array}{l}\text { - The intervention led to improvement on the majority } \\
\text { of outcome measures. }\end{array}$ \\
\hline & $\begin{array}{l}\text { - The intervention was at least as effective as comparison } \\
\text { groups. }\end{array}$ \\
\hline & $\begin{array}{l}\text { - The intervention was more effective than waiting list } \\
\text { or no intervention control groups. }\end{array}$ \\
\hline \multirow[t]{3}{*}{ Less effective } & $\begin{array}{l}\text { - The intervention led to improvement on a minority } \\
\text { of outcome measures. }\end{array}$ \\
\hline & $\begin{array}{l}\text { - The intervention was not necessarily as effective } \\
\text { as comparison groups. }\end{array}$ \\
\hline & $\begin{array}{l}\text { - The intervention was more effective than waiting list } \\
\text { or no intervention control groups. }\end{array}$ \\
\hline \multirow[t]{2}{*}{ Ineffective } & $\begin{array}{l}\text { - The intervention did not lead to improvement } \\
\text { on any of the outcome measures. }\end{array}$ \\
\hline & $\begin{array}{l}\text { - The intervention was no more effective than waiting list } \\
\text { or no intervention control groups. }\end{array}$ \\
\hline
\end{tabular}




\section{DESIGN OF EFFECTIVE E-HEALTH INTERVENTIONS}

Search strategy. Search for articles was conducted in parallel but coordinated with reviewing the diversity sample. Twenty-three articles were identified comprising four conceptual articles, ${ }^{44-47}$ four qualitative articles, ${ }^{48-51}$ five review articles, ${ }^{4,52-55}$ six empirical studies not related to the evaluation of Internet-based health interventions, ${ }^{56-61}$ and four published guidelines for website design. ${ }^{62-65}$

\section{PHASE 3: REPRESENTATIVE SAMPLING}

Aim. To "test" the emerging conceptual framework by examining whether the hypotheses generated from Phase 1 were consistent and generalizable.

Inclusion criteria and exclusion criteria. As for the diversity sample except that computer-based interventions or interventions delivered using synchronous computer-mediated communication were not excluded. These interventions were included to enable a more comprehensive test of the framework against a more representative sample of the literature.

Search strategy. Based on consultation with two experts in behavior change interventions (S.M.) and e-health (J.P.), two predefined sets of articles were sampled from two published systematic reviews. ${ }^{66,67}$ Twenty-five articles published between 2001 and 2005 were included, reporting interventions for physical activity, ${ }^{68-72}$ dietary behavior, ${ }^{73-82}$ and physical activity and dietary behavior. ${ }^{83-92}$ Fourteen articles reported Internet and e-mail-based interventions, ${ }^{68-71,75,79,81-88,90,92}$ three of which contained telemedicine components, ${ }^{84-86}$ seven articles reported computer-based interventions, ${ }^{73,74,76,78,80,89,91}$ and two articles reported telemedicine interventions. ${ }^{72,77}$

Review strategy. To test the conceptual framework, interventions were reviewed to identify any additional design features not identified from the review of the diversity sample. The associations between the presence of design features and intervention effects were then examined. Interventions included in the representative sample were also coded as more effective, less effective, and ineffective (see Table 1). The representative sample contained 15 more effective interventions, ${ }^{68,70-72,74-76,78,81,83,84,86-88,91}$ eight less effective interventions, ${ }^{73,77,79,80,85,89,90,92}$ and two ineffective interventions. ${ }^{69,82}$

\section{Results}

Eleven design features were identified from the review of the diver-

F2 T2 sity sample (Fig. 2 and Table 2). No additional features were identified from the review of the representative sample. In Figure 2 the inner circle contains four interactive design features hypothesized to mediate intervention outcome; the outer circle contains eight features hypothesized to moderate the effects of the four interactive features.

The review presented here focuses on the four interactive features: Social context and support, contacts with intervention, tailoring, and self-management. The aim of this review was to generate hypotheses about the associations between the presence of specific design features and intervention outcomes, not to engage in definitive

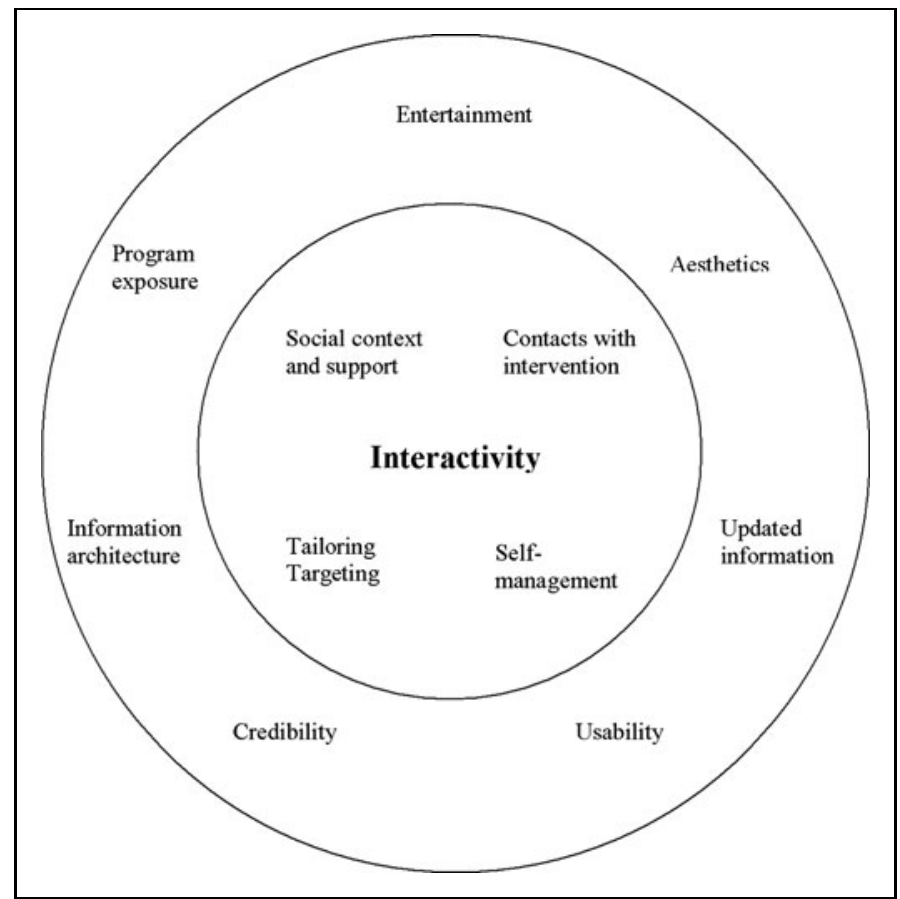

Fig. 2. Conceptual framework for the relationship between the design features described in studies of Internet-based health behavior interventions.

Table 2. Conceptual Definitions for the Design Features Identified

\section{DESIGN FEATURE} CONCEPTUAL DEFINITION

\begin{tabular}{l|l}
$\begin{array}{l}\text { Social context } \\
\text { and support }\end{array}$ & $\begin{array}{l}\text { Facilitate perceptions of social context, human } \\
\text { or human-like interaction, and social support }\end{array}$ \\
\hline $\begin{array}{l}\text { Contacts with } \\
\text { intervention }\end{array}$ & $\begin{array}{l}\text { Provide direct or mediated contact with the intervention, } \\
\text { or individuals responsible for the intervention }\end{array}$ \\
\hline $\begin{array}{l}\text { Tailoring and } \\
\text { targeting }\end{array}$ & $\begin{array}{l}\text { Provide optimally relevant information matched to } \\
\text { individual users (tailoring }\end{array}{ }^{60}$ ) or groups of user (targeting ${ }^{46}$ ) \\
\hline $\begin{array}{l}\text { Self-management } \\
\text { Entertainment }\end{array}$ & $\begin{array}{l}\text { Use of personal information for reflective } \\
\text { self-management and monitoring of health behavior }\end{array}$ \\
\hline Aesthetics & Provide content-based entertainment activities \\
\hline $\begin{array}{l}\text { Updated } \\
\text { information }\end{array}$ & $\begin{array}{l}\text { Provide an aesthetically pleasing or engaging intervention } \\
\text { intervention period }\end{array}$ \\
\hline Usability & $\begin{array}{l}\text { Facilitate users' ability to successfully navigate the } \\
\text { intervention }\end{array}$ \\
\hline Credibility & $\begin{array}{l}\text { Provide information or services to facilitate perceptions } \\
\text { of credibility }\end{array}$ \\
\hline Information & $\begin{array}{l}\text { Access to information and navigation through the } \\
\text { intervention }\end{array}$ \\
\hline architecture & $\begin{array}{l}\text { The length of time a user is entitled to engage with the } \\
\text { intervention }\end{array}$ \\
\hline Program exposure
\end{tabular}




\section{MORRISON ET AL.}

Table 3. Findings from Review of the Diversity Sample

Regarding the Association Between the Presence of Design Features and Intervention Effectiveness

DESIGN FEATURES ASSOCIATED WITH MORE EFFECTIVE INTERVENTIONS

- Automated dialogue components ${ }^{20,21,30,34}$

- Synchronous- and asynchronous-mediated peer-to-peer communication ${ }^{18,32,34,41,42}$

- Additional contacts containing behavior change techniques ${ }^{18,20,21,25,28,31,34}$

- Tailoring based on more than one variable (e.g., theoretical, behavioral, or demographic) $20,21,28,29,33,35,41$

- Tailoring based on a large and varied number of constructs (e.g., several theoretical constructs) ${ }^{18,20,29,30,34,36}$

DESIGN FEATURES ASSOCIATED WITH LESS EFFECTIVE INTERVENTIONS

- Use of avatars $^{17}$

- Providing information about other users ${ }^{24,39}$

- Additional contacts containing usage promotion techniques ${ }^{29}$

DESIGN FEATURES NOT ASSOCIATED

WITH INTERVENTION INEFFECTIVENESS

- "Ask the expert" components

- Activity planning

- Self-monitoring

hypothesis testing. Table 3 summarizes the hypotheses generated from the review of the diversity sample. Each of the four interactive design features is considered below, presenting (a) a description of how has each design feature is implemented, (b) an examination of the associations of that feature with intervention outcomes in the diversity, theoretical, and representative samples, and finally a summary of (c) the hypotheses and (d) research questions generated by the review.

\section{SOCIAL CONTEXT AND SUPPORT}

Implementation. Features providing social context and support could be grouped into three subtypes: Simulation of person-to-person interaction (e.g., automated dialogue, avatars), ${ }^{17,20,21,30,34}$ provision of synchronous- (e.g., chat rooms) ${ }^{36,41}$ or asynchronous- (e.g., discussion forums) ${ }^{18,32,34,42}$ mediated contact with other users, and provision of information about other users (e.g., social norms, vignettes). ${ }^{24,28,32,34,42}$

Associations with outcomes. From the review of the diversity sample it appears that simulation of person-to-person interaction using automated dialogue is more effective than using avatars. Two interventions in the representative sample-one more effective and one less effective-reported using simulation of person-to-person interaction using digitized speech. ${ }^{72,77}$ This suggests that the use of digitized speech is not always associated with intervention effectiveness. Automated dialogue may be more effective than avatars for simulating person-to-person interaction because users expect more from a system that looks and behaves like a human than from an overtly automated system. Qualitative feedback from users does suggest that avatar-based systems are an unrealistic substitute for human interaction. ${ }^{17}$ Current technology may not yet permit the development of systems sufficiently sophisticated to simulate real interaction. Users may also have differing preferences for interacting with human-like systems versus machine-like systems. ${ }^{49}$

From the review of the diversity sample there appeared to be a positive association between peer-to-peer-mediated communication and intervention outcome. However, although some studies reported that discussion forums and chat rooms were frequently used and helpful, ${ }^{33,34,42}$ others reported infrequent use and few changes in perceptions of social support. ${ }^{18,37,41}$ From the review of the representative sample, mediated communication with peers appeared to be used in both more and less effective interventions, but dissatisfaction with mediated communication did not appear to have adverse effects. ${ }^{84}$ No effects were found for the use of synchronous and asynchronous peer-to-peer communication in a systematic review, ${ }^{53}$ although this may be because the review was published in 2004, before the onset of Web 2.0, when peer-to-peer communication was less widely used. The effectiveness of mediated communication with peers appears to be variable and may depend on several factors including perceptions about the credibility of Internet-based peer advice, ${ }^{44,48,50}$ perceived quality of interaction, ${ }^{69,86}$ and active user involvement (i.e., users involved in posting and responding to messages may benefit more than "lurkers"). ${ }^{37,51}$

From the review of the representative sample, providing information about other users appeared to be associated with more effective interventions, ${ }^{78}$ whereas from the review of the diversity sample it was not. This may be because interventions from the diversity sample tended to include testimonials from hypothetical users, ${ }^{24}$ whereas interventions from the representative sample included testimonials from real users. ${ }^{78}$

Hypotheses. Social context and support features have varied outcomes, but providing automated dialogue components, synchronous- or asynchronous-mediated communication with peers, or information about other real users may have a positive effect on intervention outcomes.

Research questions. What makes features that provide social context and support effective? Is it because they increase perceptions of social support? Or is it because enhanced personal relevance of the information and advice provided?

\section{CONTACTS WITH INTERVENTION}

Implementation. Two types of contacts with intervention were identified: Expert-initiated contact ${ }^{18-21,24,25,28-30,36,40,42}$ and userinitiated contact. ${ }^{32,34,36,38,41}$ Expert-initiated contact could be 


\section{DESIGN OF EFFECTIVE E-HEALTH INTERVENTIONS}

grouped into two further subtypes: Contact delivering behavior change techniques (e.g., motivational emails) and contact promoting intervention usage (e.g., e-mail reminders).

Associations with outcomes. Contacts delivering behavior change techniques were more common in more effective interventions than in less effective interventions. ${ }^{7,81}$ Simple reminders were found to have a small effect on health behavior in a recent systematic review ${ }^{4}$ but were more common in less effective interventions. ${ }^{77}$ "Ask the expert" services were used in both more and less effective interventions reviewed in the diversity sample. However, "ask the expert" services were not a common feature of more effective interventions reviewed in the representative sample, suggesting that this feature may not be an essential component for an effective intervention.

The effectiveness of contacts delivering behavior change techniques may be influenced by several factors. There is some evidence that these contacts may only be effective for already engaged users of the intervention and may not engage "new" or infrequent users. ${ }^{22}$ They may also be subject to ceiling effects or context effects. Motivational e-mails provided to users who are already performing the desired behavior at baseline are likely to be redundant. ${ }^{28}$ Motivational e-mails provided within a workplace context run the risk of being ignored in an already overflowing inbox..$^{28,42}$ Allowing users to choose to receive mobile phone or e-mail reminders increased their perceived personal control over implementing their physical activity intentions. ${ }^{21}$

Hypotheses. Contacts delivering behavior change techniques may be more effective than simple reminders to use the intervention.

Research questions. Are contacts delivering behavior change techniques (e.g., tailoring, social support, or goal reminders) more effective than those that do not? Why do user-initiated contacts such as "ask the expert" services appear to have little influence on intervention outcome? Do users prefer to seek advice from peers for some health behaviors (e.g., smoking cessation) $?^{33}$ How important are the characteristics of the "expert," the user, and the health topic?

\section{TAILORING}

Implementation. Tailoring is the provision of information relevant to one individual person ${ }^{60}$ and can be based on theoretical constructs, behavior, or demographic characteristics. ${ }^{55}$

Associations with outcomes. Nearly all the studies used a tailored design, so no comparison could be made with non-tailored designs. The number of variables of individual constructs used to deliver tailoring did not appear to differ between more and less effective interventions reviewed in the representative sample. From the review of the diversity sample and in a systematic review of tailored print materials ${ }^{55}$ information and advice appeared to be more effective if they were tailored to more than one variable. The effect of tailoring variables has been proposed to be hierarchical (i.e., tailoring based on theoretical constructs is more effective than tailoring based on be- havior), which is more effective than tailoring based on demographic characteristics. $^{55}$

Hypotheses. Tailoring based on greater numbers of variables may be more effective than tailoring based on just one variable.

Research questions. How should tailoring be implemented? What is the optimal balance between tailored and non-tailored information? Is tailoring more effective if users choose to receive it? Is tailoring effective because it enhances perceptions of personal relevance or because it resembles face-to-face interaction?

\section{SELF-MANAGEMENT}

Implementation. Two types of self-management features were identified: Activity planning and self-monitoring.

Associations with outcomes. The review of both the diversity and representative samples found that activity planning and selfmonitoring were used in both more and less effective interventions. Self-management features appeared to be well liked by users, ${ }^{21,27,33}$ but recent evidence suggests they are not always frequently used. ${ }^{18}$ This finding is unexpected as there is good evidence for the effectiveness of self-management strategies in contexts other than Internet-based interventions. ${ }^{52,54,56}$ Recent meta-analyses have found that interventions that included self-monitoring components were significantly more effective, particularly when provided in conjunction with other components (e.g., goal setting and feedback on performance). ${ }^{52,54}$

A recent meta-analysis of interventions delivered using the Internet reported that goal setting and action planning had a significant impact on behavior but self-monitoring $\operatorname{did}_{\text {not. }}{ }^{4}$ Published intervention protocols often do not specify how activity was planned, what behaviors were monitored, or how behavior was monitored, which makes it difficult to explain when and why these techniques may be effective or ineffective. These mixed findings may reflect qualitative differences between the processes of activity planning versus selfmonitoring. The latter may require more intensive and sustained effort, which may benefit from human interaction and support.

Hypotheses. Self-management strategies that include behavior change techniques theoretically predicted to function synergistically will be more effective than those omitting theoretically relevant techniques.

Research questions. What makes self-management features effective? Are these features more effective when they are structured (e.g., users choose from predefined options) or unstructured? How important is providing feedback on activity planning and selfmonitoring? Is activity planning more effective than self-monitoring?

\section{Discussion}

This review used techniques from CIS to develop a conceptual framework summarizing the design of Internet-based health 


\section{MORRISON ET AL.}

interventions. The framework proposes that four interactive design features mediate intervention outcomes: Social context and support, contacts with intervention, tailoring, and selfmanagement. It is hypothesized that interventions may be associated with more positive outcomes if they provide social support using automated dialogue, peer-to-peer-mediated communication, or information about other real users, additional contacts that incorporate behavior change techniques, and tailoring based on combinations of variables. Further research is needed to understand the effects of user-initiated "ask the expert" services and self-management features. These design features are not specific to Internet-based health interventions. Therefore the hypotheses and questions generated by this review may also have implications for the delivery of other e-health and telemedicine applications such as remote patient monitoring, telepsychiatry, home healthcare, and decision support tools.

The conceptual framework includes some of the design features proposed in existing frameworks ${ }^{9-12}$ (e.g., tailoring, self-monitoring, aesthetics, credibility, usability, and information architecture). However, the framework also includes new features not defined within existing frameworks (e.g., social context and support and contacts with intervention). The conceptual framework proposed in this review goes beyond existing frameworks by specifying which design features contribute to "interactivity" and by developing hypotheses about how these interactive features may influence healthrelated outcomes.

The aim of this review was to provide a detailed critical analysis of a diversity sample and a representative sample of the literature, rather than an exhaustive systematic review of all Internet-based health interventions. The hypotheses and framework proposed do not represent all possible interpretations but present one potentially useful perspective. Analysis of intervention design was limited by the level of detail provided by authors. The literature could benefit from more explicit reporting of the development and implementation of interventions ${ }^{93}$ and/or the sharing of intervention details. ${ }^{94}$ It is likely that factors other than intervention design (e.g., quality of theoretical content) will also have important effects on intervention outcome. Because few ineffective interventions could be identified an important comparison group was missing. To fully understand effective intervention design there is a real need to publish reports on both effective and ineffective interventions.

Improving our understanding about how the design of e-health interventions promotes optimal outcomes will help these interventions to realize their full potential. Further research is needed to understand how and why specific design features may affect intervention outcome by addressing the questions generated from this review. Systematic quantitative approaches ${ }^{95}$ can be used to identify what dosage and combination of features will produce optimal intervention outcomes. Furthering our understanding of which design features add to or take away from intervention effectiveness will also help researchers and practitioners to decide if, when, and how the Internet or other e-health technologies will be the most effective mode of delivery for a given intervention. ${ }^{96}$

\section{Author Disclosure Statement}

No competing financial interests exist.

\section{REFERENCES}

1. Eng TR. The ehealth landscape: A terrain map of emerging information and communication technologies in health and health care. Princeton, NJ: The Robert Wood Johnson Foundation, 2001

2. Portnoy DB, Scott-Sheldon LAJ, Johnson BT, Carey MP. Computer-delivered interventions for health promotion and behavioral risk reduction: A meta-analysis of 75 randomized controlled trials, 1988-2007. Prev Med 2008;47:3-16.

3. Wantland DJ, Portillo CJ, Holzemer WL, Slaughter R, McGhee EM. The effectiveness of web-based vs. non-web-based interventions: A meta-analysis of behavioral change outcomes. J Med Internet Res 2004;6:e40.

4. Webb TL, Joseph J, Yardley L, Michie S. Using the Internet to promote health behavior change: A systematic review and meta-analysis of the impact of theoretical basis, use of behavior change techniques, and modes of delivery on efficacy. J Med Internet Res 2010;12:e4.

5. Nguyen HO, Carrieri-Kohlman V, Rankin SH, Slaughter R, Stulbarg MS. Internet-based patient education and support interventions: A review of evaluation studies and directions for future research. Comput Biol Med 2004:34:95-112.

6. Abraham C, Michie S. A taxonomy of behavior change techniques used in interventions. Health Psychol 2008;27:379-387.

7. Green LW, Kreuter MW. Health promotion and planning: An educational and ecological approach. Mountain View, CA: Mayfield, 1999.

8. Kok G, Schaalma $H_{1}$ Ruiter RAC, Van Empelen P, Brug J. Intervention mapping: Protocol for applying health psychology theory to prevention programmes. $J$ Health Psychol 2004;9:85-98.

9. Crutzen R, De Nooijer J, Brouwer W, Oenema A, Brug J, De Vries NK. A conceptual framework for understanding and improving adolescents' exposure to Internet-delivered interventions. Health Promot Int 2009;24:277-284.

10. Fogg BJ. Persuasive technology: Using computers to change what we think and do. San Francisco: Morgan Kaufmann Publishers, 2003.

11. Ritterband LM, Thorndike FP, Cox DJ, Kovatchev BP, Gonder-Frederick LA. A behavior change model for Internet interventions. Ann Behav Med 2009;38:18-27.

12. Walther JB, Pingree $S$, Hawkins RP, Buller DB. Attributes of interactive online health information systems. J Med Internet Res 2005;7:e33.

13. Dixon-Woods M, Cavers D, Agarwal $S$, Annandale E, Arthur A, Harvey J, Hsu R, Katbamna $S$, Olsen R, Smith L, Riley R, Sutton AJ. Conducting a critical interpretive synthesis of the literature on access to healthcare by vulnerable groups. BMC Med Res Methodol 2006;6:35.

14. Higgins JPT, Green S, eds. Cochrane handbook for systematic reviews of interventions. Version 5.1.0 [updated March 2011] [Online]. Available at www.cochrane-handbook.org/ (last accessed October 1, 2010).

15. Strauss AL, Corbin JM. Basics of qualitative research: Grounded theory procedures and techniques. Newbury Park, CA: Sage Publications, 1983

16. Marshall MN. Sampling for qualitative research. Fam Pract 1996;13:522-526.

17. Bickmore T, Gruber A, Picard R. Establishing the computer-patient working alliance in automated health behavior change interventions. Patient Educ Couns 2005;59:21-30

18. Ferney SL, Marshall AL, Eakin EG, Owen N. Randomized trial of a neighborhood environment-focused physical activity website intervention. Prev Med 2009;48:144-150.

19. Hageman PA, Walker SN, Pullen CH. Tailored versus standard Internet-delivered interventions to promote physical activity in older women. J Geriatr Phys Ther 2005;28:28-32

20. Hurling $R$, Catt $M$, De Boni M, Fairley BW, Hurst $T$, Murray $P$, Richardson A, Sodhi JS. Using Internet and mobile phone technology to deliver an automated 
physical activity program: Randomized controlled trial. J Med Internet Res 2007;9:e7.

21. Hurling R, Fairley BW, Dias BM. Internet-based exercise intervention systems: Are more interactive designs better? Psychol Health 2006;21:757-772.

22. Leslie $E$, Marshall AL, Owen N, Bauman A. Engagement and retention of participants in a physical activity website. Prev Med 2005;40:54-59.

23. Marks JT, Campbell MK, Ward DS, Ribisl KM, Wildemuth BM, Symons MJ. A comparison of web and print media for physical activity promotion among adolescent girls. J Adolesc Health 2006;39:96-104.

24. Marshall AL, Leslie ER, Bauman AE, Marcus BH, Owen N. Print versus website physical activity programs. A randomized trial. Am J Prev Med 2003;25:88-94

25. Napolitano MA, Fotheringham M, Tate D, Sciamanna C, Leslie $E_{1}$ Owen $N$ Bauman A, Marcus B. Evaluation of an Internet-based physical activity intervention: A preliminary investigation. Ann Behav Med 2003;25:92-99.

26. Parrott MW, Tennant LK, Olejnik S, Poudevigne MS. Theory of planned behavior: Implications for an email-based physical activity intervention. Psychol Sport Exerc 2008;9:511-526.

27. Sciamanna CN, Lewis $B$, Tate $D$, Napolitano MA, Fotheringham M, Marcus BH. User attitudes toward a physical activity promotion website. Prev Med 2002;35:612-615

28. Spittaels H, De Bourdeaudhuij I, Brug J, Vandelanotte C. Effectiveness of an online computer-tailored physical activity intervention in a real-life setting. Health Educ Res 2007;22:385-396.

29. Spittaels H, De Bourdeaudhuij I, Vandelanotte C. Evaluation of a websitedelivered computer-tailored intervention for increasing physical activity in the general population. Prev Med 2007;44:209-217.

30. Brendryen $H$, Drozd F, Kraft P. A digital smoking cessation program delivered through the Internet and cell phone without nicotine replacement (Happy Ending): Randomized controlled trial. J Med Internet Res 2008;10:e51.

31. Danahar BG, Smolkowski K, Seeley JR, Severson HH. Mediators of a successful web-based smokeless tobacco cessation program. Addict 2008;103:1706-1712.

32. Patten CA, Croghan IT, Meis TM, Decker PA, Pingree $S$, Colligan RC, Dornelas EA, Offord KP, Boberg EW, Baumberger RK, Hurt RD, Gustafson DH. Randomized clinical trial of an Internet-based versus brief office intervention for adolescent smoking cessation. Patient Educ Couns 2006;64:249-258.

33. Patten CA, Rock E, Meis TM, Decker PA, Colligan RC, Pingree $S$, Dornelas EA, Offord KP, Boberg EW, Gustafson DH. Frequency and type of use of a home-based, Internet intervention for adolescent smoking cessation. J Adolesc Health 2007;41:437-443.

34. Severson HH, Gordon JS, Danahar BG, Akers L. ChewFree.com: Evaluation of a web-based cessation program for smokeless tobacco users. Nicotine Tob Res 2008;10:381-391

35. Booth AL, Nowson CA, Matters H. Evaluation of an interactive, Internet-based weight loss program: A pilot study. Health Educ Res 2008;23:371-381.

36. McConnon A, Kirk SFL, Cockroft JE, Harvey EL, Greenwood DC, Thomas JD, Ransley JK, Bojke L. The Internet for weight control in an obese sample: Results of a randomised controlled trial. BMC Health Serv Res 2007;7;206.

37. McConnon A, Kirk SFL, Ransley JK. Process evaluation of an Internet-based resource for weight control: Use and views of an obese sample. J Nutr Educ Behav 2009;41:261-267.

38. Franko DL, Cousineau TM, Trant M, Green TC, Rancourt D, Thompson D, Ainscough J, Mintz LB, Ciccazzo M. Motivation and self-efficacy, physica activity, and nutrition in college students: Randomized controlled trial of an Internet-based education program. Prev Med 2008:47:369-377.

39. Park A, Nitze S, Kritsch K, Kattelmann K, White A, Boeckner L, Lohse B, Hoerr S, Greene $G$, Zhang Z. Internet-based interventions have potential to affect shortterm mediators and indicators of dietary behavior of young adults. $J$ Nutr Educ Behav 2008;40:288-297.

40. Berman $R L H$, Iris $M A$, Bode $R$, Dregenberg $C$. The effectiveness of an online mind-body intervention for older adults with chronic pain. J Pain 2009;10:68-79.
41. Nguyen HO, Donesky-Cuenco D, Wolpin S, Rineke LF, Benditt JO, Paul SM, Carrieri-Kohlman V. Randomized controlled trial of an Internet-based versus face-to-face dyspnea self-management program for patients with chronic obstructive pulmonary disease: Pilot study. J Med Internet Res 2008;10:e9.

42. Lorig KR, Pitter PL, Laurent DD, Plant K. The Internet-based arthritis selfmanagement program: A one-year randomized trial for patients with arthritis or fibromyalgia. Arthritis Rheum 2008;59:1009-1017.

43. Bowen D, Ludwig A, Bush N, Unruh HK, Meischke $H$, Wooldridge JA, Robbins R. Early experience with a web-based intervention to inform risk of breast cancer. J Health Psychol 2003;8:175-186.

44. Cline RJW, Haynes KM. Consumer health information seeking on the Internet: The state of the art. Health Educ Res 2001;16:671-692.

45. Danahar BG, McKay GH, Seeley JR. The information architecture of behavior change websites. J Med Internet Res 2005;7:e12.

46. Kreuter MW, Skinner CS. Tailoring: What's in a name? Health Educ Res 2000;15:1-4.

47. Kreuter MW, Strecher VJ, Glassman B. One size does not fit all: The case for tailoring print materials. Ann Behav Med 1999;21:276-283.

48. Eysenbach G, Köhler C. How do consumers search for and appraise health information on the world wide web? Qualitative study using focus groups, usability tests, and in depth interviews. Br Med J 2002;324:573-577.

49. Farzanfar R. When computers should remain computers: A qualitative look at the humanization of health care technology. Health Inform J 2006;12: $239-254$.

50. Kelly W, Connolly V, Bilous R, Stewart A, Nag S, Bowes D, Loader B, Muncer S. Reader beware: Diabetes advice on the web. Pract Diabetes Int 2002;19:108-110.

51. Smaglik $P$, Hawkins RP, Pingree $S$, Gustafson DH, Boberg E, Bricker E. The quality of interactive computer use among HIV-infected individuals. J Health Commun 1998;3:53-68

52. Dombrowski SU, Sniehotta FF, Avenell A, Johnston M, MacLennan G, AraújoSoares $\mathrm{V}$. Identifying active ingredients in complex behavioural interventions for obese adults with obesity-related co-morbidities or additional risk factors for co-morbidities: A systematic review. Health Psychol Rev (in press).

53. Eysenbach G, Powell J, Englesakis M, Rizo C, Stern A. Health related virtual communities and electronic support groups: Systematic review of the effects of online peer to peer interactions. BMJ 2004;328:1166-1170.

54. Michie S, Abraham C, Whittington C, McAteer J, Gupta S. Effective techniques in healthy eating and physical activity interventions: A meta-regression. Health Psychol 2009;28:690-701.

55. Noar SM, Benac CN, Harris MS. Does tailoring matter? Meta-analytic review of tailored print health behavior change interventions. Psychol Bull 2007;133: 673-693.

56. Anderson ES, Winett RA, Wojcik JR. Self-regulation, self-efficacy, outcome expectations, and social support: Social cognitive theory and nutrition behavior. Ann Behav Med 2007;34:304-312.

57. Fogg BJ, Marshall J, Kameda T, Soloman J, Rangnekar A, Boyd J, Brown B. Web credibility research: A method for online experiments and early study results. Proceedings of the ACM CHI Conference on Human Factors in Computing Systems. 2001;295-296.

58. Fogg BJ, Marshall J, Laraki O, Osipovich A, Varma C, Fang N, Paul J, Rangneka JS, Shon J, Swani P, Treinen M. What makes websites credible? A report on a large quantitative survey. Proceedings of the ACM CHI Conference on Human Factors in Computing Systems. 2001;61-68.

59. Fogg BJ, Marshall J, Osipovich A, Varma C, Laraki O, Fang N, Paul J, Rangnekar A Shon J, Swani P. Treinen M. Elements that affect web credibility: Early results from a self-report study. Proceedings of the ACM CHI Conference on Human Factors in Computing. Systems 2000;287-288.

60. Kreuter MW, Bull FC, Clark EM, Oswald DL. Understanding how people process health information: A comparison of tailored and nontailored weight-loss materials. Health Psychol 1999;18:487-494. 


\section{MORRISON ET AL.}

61. van der Heijden H. Factors influencing the usage of websites: The case of a generic portal in the Netherlands. Inform Manage 2003;40:541-549.

62. Fogg BJ. Standford guidelines for web credibility. A research summary from the Stanford Persuasive Technology Lab [Online]. 2002. Available at http:// credibility.stanford.edu/guidelines/index.html (last accessed October 12. 2010).

63. Krug S. Don't make me think. A common sense approach to web usability. Berkeley, CA: New Riders, 2006.

64. Sillence $E$, Briggs $P$, Fishwick $L$, Harris P. Guidelines for developing trust in health websites. Proceedings of the 14th International World Wide Web Conference. 2005;1026-1027.

65. U.S. Department of Health and Human Services. Usability.gov. Your guide for developing usable and useful websites. Available at www.usability.gov/ (last accessed October 12, 2010).

66. Norman GJ, Zabinski MF, Adams MA, Rosenberg DE, Yaroch AL, Atienza AA. A review of ehealth interventions for physical activity and dietary behavior change. Am J Prev Med 2007;33:336-345.

67. van den Berg MH, Schoones JW, Vliet Vlieland TPM. Internet-based physical activity interventions: A systematic review of the literature. J Med Internet Res 2007;9:e26.

68. Hager RL, Hardy A, Aldana SG, George JD. Evaluation of an Internet, stage-based physical activity intervention. Am J Health Educ 2002;33: 329-335.

69. Kosma M, Cardinal BJ, McCubbin JA. A pilot study of a web-based physical activity motivational program for adults with physical disabilities. Disabil Rehabil 2005;27:1435-1442.

70. McKay GH, King D, Eakin EG, Seeley JR, Glasgow RE. The Diabetes Network Internet-based physical activity intervention. A randomized pilot study. Diabetes Care $2001 ; 24: 1328-1334$.

71. Palmer S, Graham G, Elliot E. Effects of a web-based health program of fifth grade children's physical activity knowledge, attitudes and behavior. Am J Health Educ 2005;36:86-93.

72. Pinto BM, Friedman R, Marcus BH, Kelley H, Tennstedt S, Gillman MW. Effects of a computer-based, telephone-counseling system on physical activity. Am J Prev Med 2002;23:113-120.

73. Anderson ES, Winett RA, Wojcik JR, Winett SG, Bowden T. A computerized social cognitive intervention for nutrition behavior: Direct and mediated effects on fat, fiber, and vegetables, self-efficacy, and outcome expectancies among food shoppers. Ann Behav Med 2001;23:88-100.

74. Baranowski T, Baranowski J, Cullen KW, Marsh T, Islam N, Zakeri I, Honess-Morreale L, deMoor C. Squire's Quest! Dietary outcome evaluation of a multimedia game. Am J Prev Med 2003;24:52-61.

75. Block G, Block T, Wakimoto P, Block $\mathrm{CH}$. Demonstration of an e-mailed worksite nutrition intervention program [abstract]. Prev Chronic Dis 2004;1:A06.

76. Block G, Wakimoto P, Metz D, Fujii ML, Feldman N, Mandel R, Sutherland B. A randomized trial of the Little by Little CD-ROM: Demonstrated effectiveness in increasing fruit and vegetable intake in a low-income population [abstract]. Prev Chronic Dis 2004;1:A08.

77. Delichatsios HK, Friedman R, Glanz K, Tennstedt S, Smigelski C, Pinto B, Kelley H, Gillman MW. Randomized trial of a "talking computer" to improve adults' eating habits. Am J Health Promot 2001;15:215-224.

78. Irvine BK, Ary DV, Grove D, Gilfillan-Mortan L. The effectiveness of an interactive multimedia program to influence eating habits. Health Educ Res 2004:19:290-305.

79. McKay GH, Glasgow RE, Feil EG, Boles SM, Barrera M Jr. Internet-based diabetes self-management and support: Initial outcomes from the Diabetes Network Project. Rehabil Psychol 2002;47:31-48.

80. Oenema A, Tan F, Brug J. Short-term efficacy of a web-based computer-tailored nutrition intervention: Main effects and mediators. Ann Behav Med 2005;29:54-63.
81. Papadaki A, Scott JA. The Mediterranean Eating in Scotland Experience Project: Evaluation of an Internet-based intervention promoting the Mediterranean diet. Br J Nutr 2005;94:290-298.

82. Verheijden M, Bakx CJ, Akkermans R, van den Hoogen H, Godwin MN, Rosser W, van Staveren W, van Weel C. Web-based targeted nutrition counselling and social support for patients at increased cardiovascular risk in general practice: Randomized controlled trial. J Med Internet Res 2004;6:e44.

83. Frenn M, Malin S, Brown RL, Greer Y, Fox J, Greer J, Smyczek S. Changing the tide: An Internet/video exercise and low-fat diet intervention with middle school students. Appl Nurs Res 2005;18:13-21.

84. Harvey-Berino J, Pintauro S, Buzzell P, Casey Gold E. Effect of Internet support on the long-term maintenance of weight loss. Obes Res 2004;12:320-329.

85. Harvey-Berino J, Pintauro S, Buzzell P, DiGiulio M, Casey Gold B, Moldovan C, Ramirez E. Does using the Internet facilitate the maintenance of weight loss? Int J Obes 2002;26:1254-1260.

86. Harvey-Berino J, Pintauro SJ, Casey Gold E. The feasibility of using Internet support for the maintenance of weight loss. Behav Modif 2002;26:103-116.

87. Kypri K, McAnally HM. Randomized controlled trial of a web-based primary care intervention for multiple health risk behaviors. Prev Med 2005;41:761-766.

88. Plotnikoff RC, McCargar $\sqcup$, Wilson PM, Loucaides CA. Efficacy of an email intervention for the promotion of physical activity and nutrition behavior in the workplace context. Am J Health Promot 2005;19:422-429.

89. Prochaska JJ, Sallis JF. A randomized controlled trial of single versus multiple health behavior change: Promoting physical activity and nutrition among adolescents. Health Psychol 2004;23:314-318.

90. Southard BH, Southard DR, Nuckolls J. Clinical trial of an Internet-based case management system for secondary prevention of heart disease. J Cardiopulm Rehabil 2003;23:341-348.

91. Vandelanotte C, De Bourdeaudhuij I, Sallis JF, Spittaels H, Brug J. Efficacy of sequential or simultaneous interactive computer-tailored interventions for increasing physical activity and decreasing fat intake. Ann Behav Med 2005;29:138-146.

92. Veverka DV, Anderson J, Auld GW, Coulter GR, Kennedy C, Chapman PL. Use of the stages of change model in improving nutrition and exercise habits in enlisted Air Force men. Mil Med 2003;168:373-379.

93. Michie S, Fixsen D, Grimshaw JM, Eccles MP. Specifying and reporting complex behaviour change interventions: The need for a scientific method. Implement Sci 2009;4:40.

94. Kraft P, Yardley L. Current issues and new directions in psychology and health: What is the future of digital interventions for health behaviour change? Psychol Health 2009;24:615-618.

95. Collins LM, Murphy SA, Strecher V. The multiphase optimization strategy (MOST) and the sequential multiple assignment randomized trial (SMART). New methods for more potent eHealth interventions. Am J Prev Med 2007;32(5 Suppl):S112-S118.

96. Griffiths F, Lindenmeyer A, Powell J, Lowe $P$, Thorogood M. Why are healthcare interventions delivered over the Internet? A systematic review of the published literature. J Med Internet Res 2006;8:e10.

Address correspondence to:

Leanne G. Morrison, Ph.D.

School of Psychology

University of Southampton

Southampton, Hampshire SO17 1BJ

United Kingdom

E-mail:1m904@soton.ac.uk

Received: April 5, 2011

Revised: June 23, 2011

Accepted: July 13, 2011 
AU1 Verify academic degrees added and correct as needed.

AU2 Original read 421. Change to 42 ok?

AU3 Update with year, volume, pages or at minimum give DOI.

AU4 Give location of meeting and publishing (sponsoring) society. Also in references 58 and 59.

AU5 Give location of meeting and publishing (sponsoring) society.

AU6 Verify academic degree added correctly. 